MedieKultur | Journal of media and communication research | ISSN 1901-9726

Article - Open section

\title{
'Don Fabio' and the taming of the three lions: the discursive construction of a foreign England manager's identity in the sports online written media
}

\section{Dermot Brendan Heaney}

MedieKultur 2013, 54, 159-180

Published by SMID | Society of Media researchers In Denmark | www.smid.dk The online version of this text can be found open access at www.mediekultur.dk

This article considers the appointment of a foreign manager to coach a national football team from the perspective of discursive identity construction. The data is comprised of three corpora of online versions of newspaper articles, each corresponding to a phase in Fabio Capello's first two years of tenure. Reflecting current trends in Critical Discourse Analysis, qualitative close analysis is carried out on two articles from each corpus while quantitative analysis is extended across each corpus to identify salient and consistent aspects of discursive identity construction. Exploiting the multi-disciplinary basis of CDA, the data is examined in terms of transitivity, lexis (comprising vocabulary, collocation, deixis, and intertextuality), and narrative identity construction. Micro-analysis of grammatical and linguistic patterns is applied to indicate patterns in press coverage in each phase, and a corresponding overview considers how aspects of identity work diffused through each corpus cohere into general storylines.

\section{Introduction}

The starting point for this analysis of the discursive construction of 'out-group' and 'ingroup' identity in the national sports media is a moment of crisis in English football. Under the unsuccessful stewardship of manager Steve McClaren, the national team has been eliminated from the European Championship. McClaren is sacked in November 2007, and 
in December of the same year, the English Football Association names the renowned Italian coach Fabio Capello as his successor.

\title{
Media Discourse, mediasport, and identity construction
}

As McKay (2006) notes, print media texts perform a wide variety of functions:

They supply accounts of reality and construct particular forms of knowledge and pleasure: they inform and educate, they sell products, they tell stories, they entertain, they connect us with others, they help form our identities, they influence trends and mobilise opinion.

Most of the functions listed above feature more or less prominently in written sports coverage. Lawrence Wenner's description of the influence of mediated sports discourse in the United States has become increasingly appropriate for other contexts as a result of developments in technology and the blurring of boundaries between sports and commerce:

\begin{abstract}
Mass-communicated and highly commercialized sports culture is easily related to myriad issues concerning socialization, interpersonal communication, value formation, racial and gender assessments, and the balance of political power. Whether a sports fan or not, every individual in America is to some degree influenced by the communication of sports culture (Wenner, 1989, p. 16).
\end{abstract}

Wenner (1989, p. 16) argues against regarding sports media discourse as too marginal to constitute a focus for serious media analysis that, on the contrary, "is often initiated by [...] the repercussions of overtly sexual and violent content in television programs, stereotyping and 'antisocial' behavior in children's programs and distorted messages in television advertising." Wenner (1989, p. 16) posits that "these issues and others are plentiful in the communication of sport." The aim of this paper is to contribute to the development of sports communication enquiry through the issue of discursive construction in written media of a foreign national identity for England's newly appointed Italian coach and the construction of 'national' identity for the players and FA functionaries who represent the 'nation'.

Michael Billig (1995, p. 119) spells out the relevance of sport coverage to the study of national identity construction in a media context: "All the papers, whatever their politics, have a section in which the flag is waved with regular enthusiasm." However, he adds that "such pleasures cannot be innocent" and provides an indication of why not:

As men scan for the results of their favoured team, they read of the deeds of other men doing battle, in the cause of that larger body, the team. And often the team is the nation battling for honour against foreigners (Billig 1995, p. 124).

According to Wenner (1998, p. xiii), "the cultural fusing of sport with communication" has created "a new genetic strain called Mediasport." These technological changes have, as Whitson (1998, p. 52) argues, further extended "the construction of communities of sporting interest." It is possible that these developments have had a bearing on processes of discursive 
national identity construction and affirmation through mediated coverage of the national team, as the global range of the internet can now serve to maintain the national identities of those who for (mainly) economic reasons no longer reside in their 'homeland' at all.

Fairclough claims that "media discourse is able to exercise a pervasive and powerful influence in social reproduction because of the very scale of the modern mass-media and the extremely high level of exposure of whole populations to a relatively homogenous output" (2001, p. 45). The hypertextual multimodal apparatus of online written media and its influence on reading patterns and audience reception adds a further dimension to the reiteration and recreation processes that Fairclough (2003) has called "chains of texts", which one can start by analysing quantitatively in order to trace how they extend across a context like sports coverage in the process of discursively constructing national identity.

\section{Media sports celebrity and critical discourse analysis}

This commentary on discursive identity construction draws on the methodology of CDA (see Fairclough, 1995; Bloor \& Bloor, 2007) and Identity Theory (see Wodak et al., 2009; Benwell \& Stokoe, 2006). It is axiomatic that "CDA analysis shows how discourse help[s] maintain power structures and supports discrimination" (Bloor \& Bloor, 2007, p. 85), by implication to the detriment of disadvantaged social, gender, ethnic, and racial groups. Fabio Capello does not fall into an 'underprivileged' category: he is an immensely successful professional who belongs to the new class of super-privileged, endlessly upwardly mobile individuals who have been transformed into global celebrities by the dynamics of what Wenner calls 'MediaSport'. Capello does not require an academic paper revealing how his image suffers as a result of discursive out-group derogation. The real focus of this commentary is, of course, the national sports media and how it discursively constructs identity when confronted by a perceived threat to that identity.

\section{Football and national identity}

Theorists in various disciplines point out that national teams are a potent expression of national identity and that the sports pages of newspapers are among the most common sites for this to be 'flagged' (see Porter, 2004, p. 31). Adrian Beard spells out the variety of Englishness embodied by the national team:

\footnotetext{
The dominant British stereotype presented abroad - usually spoken of in terms of Englishness -involves courage, commitment and fighting spirit. At times of sporting excitement and some national success, the same stereotype appears in British sports coverage too, suggesting that stereotypes are not exclusively about attitudes to foreigners. They are also used within the nation itself, providing, that is, that there are positive features, which can give a sense of national identity and well-being (Beard, 1998, p. 34)
}

The appointment of a foreigner as England manager briefly made it more difficult to take this expression of cultural identity for granted. 
The extent to which a successful national team embodies an ideal of national identity is explained by the 'sporting fallacy', "a popular misconception characterised as the tendency to see English sporting performances as somehow symptomatic of the nation's health" (Porter, 2004, p. 35). For the English, Wembley 1966 is seen as an important watershed. In that year, under Alf Ramsey, the national team beat West Germany to win the World Cup for the first time. Since then, as Porter writes, "the success or otherwise of the national team playing the national game in international competition [has] become a very sensitive indication of the state of the nation" (Porter, 2004, p. 35). However, there is evidence to suggest that the game is widely regarded as an index of national moral fibre and cultural vigour too; in other words, the England jersey is knitted from the fabric of English society.

\section{Nation: an imaginary construct}

It needs to be pointed out from the start that there is an underlying fluidity and contingency to any critique of the construction of national identity. Wodak et al. suggest that "national identities are [...] malleable, fragile and, frequently ambivalent and diffuse" (Wodak et al., 2009, p. 4), so shifting indeed as to merge, overlap with, and simultaneously stand out from other communities that they closely resemble. If this is true, there appear to be good grounds for agreeing with Benedict Anderson's (1983) conception of nations as essentially 'imagined communities'. Through close linguistic analysis, this paper considers the role media discourse plays in shaping how the 'nation' does its collective imagining and the stories it tells to fellow 'nationals' when a foreigner is entrusted with restoring lustre to a cherished symbol like the national football team.

\section{The data}

\section{The corpora}

Articles about the English national team and its manager tend to be sporadic, coinciding with the build-up to and immediate aftermath of international matches.

The texts selected do not include match reports, which tend to focus on players' performances and on topical moments in the matches themselves. Instead, the selected texts centre on responses to Fabio Capello. The Internet proved a valuable resource for assembling three compact corpora, which were divided as follows: 1 ) a selection of online articles about the appointment of Capello as the England manager, taken from across the spectrum of written media ( 6 redtop tabloids, generally associated with sensationalism and entertainment; 6 blacktop tabloids, characterised by less sensationalism and more serious news coverage; and 4 broadsheets - spanning the period from December 2007 to February 2008); 2) 14 articles (8,903 words) written between the end of 2007 and the end of 2008, focusing on the new training regime and ethos introduced by Capello (the sample comprised 1 redtop, 6 blacktops, and 6 broadsheets; 3 ) a corpus comprised of four long articles taken exclusively from the broadsheets, totalling 3,155 words and spanning the period from 
December 2007 to November 2009, each featuring lengthy analysis of Capello and redefining him in light of his achievements during this period. The three corpora - covering the 'spontaneous' press reaction to the news of his appointment, adjustment to the changes he introduces, and a more 'considered' appraisal of his 'success' - allow analysis to be carried out from number of perspectives.

\section{Approach to text and discourse}

Using discourse to understand the dynamics of identity construction makes it necessary to define discourse itself and to account for the aspects of it that are the focus of the analysis. The basic component of discourse is recognised as the text, namely, "a complete linguistic interaction (spoken or written), preferably from beginning to end" (Eggins, 2004, p. 4). However, the understanding of what actually constitutes a text has undergone considerable revision among theorists. The work of Kress and van Leeuwen $(1998,2001,2004)$ has been particularly instrumental in extending the meaning of text to include images. On the basis of this more inclusive definition of text, van Leeuwen (2004, pp. 7-14) proposes the following typology:

Speech genres combine language and action in an integrated whole, written genres combine language, image and graphics in an integrated whole. Speech genres should therefore be renamed "performed" genres and written genres "inscribed genres" (cited in Petroni 2011, p. 43).

The above position has developed into more or less the orthodox one, particularly in the ambit of digital communication, in which "thanks to digitalisation, no semiotic resource prevails or can live separately from the others: all the resources are conjointly employed and cooperate within a flat hierarchy and are equally responsible for meaning creation" (Petroni, 2011, p. 42).

However, certain variables within the data made it difficult to factor images into this qualitative-quantitative model with reliable consistency. The multi-modal format of the online articles in the corpora did include photographs and captions, but they were not always present, and even when they were, their positions and sizes were neither standard nor consistent. As Petroni states, "production and interpretation are intertwined and it is impossible to have the former without the latter [...] Even the choice of media, or tools and materials, implies an interpretation and the perceived meaning is perceived and decoded accordingly" (Petroni, 2011, p. 47). This opens rich vistas for qualitative analysis but also implies significant challenges for quantitative investigation. The links and advertising in headers, footers, and sidebars do not necessarily perform the same function on different online newspaper sites. In addition, such visuals are frequently not in view or can be viewed differently (if at all) by readers who, for example, choose to use the zoom functions. The mere act of scrolling down means that various visuals actually disappear. The written text that forms the corpus, on the contrary, is more or less continuous on the scrolled web page; it is, so to speak, the gel that holds the total semiotic mix of online articles together. The 
following qualitative-quantitative analysis relies on this sole, though not marginal, aspect of inscribed texts, while acknowledging that a multi-modal semiotics would shed further interesting light on a qualitative analysis of discursive identity construction in this context.

\section{Analytical framework}

\section{Identity as a construct}

Underlying the various approaches to identity theory is a historical dichotomy between essentialist and constructivist views, namely between the conviction that it derives from a 'true' inner self "lurking behind discourse" and the opposing idea that it is "actively, ongoingly, dynamically constituted in discourse" (Benwell \& Stokoe, 2006, p. 4). Identity is often attributed to out-group members not by a single in-group member but by an entire 'community of practice' (Eckhert \& McConnell-Ginet, 1992, p. 464), in this case composed largely of sports journalists, which expresses impressions of the foreign national to an 'interpretative community' (Fish, 1980) of sports readers, who quite probably believe in what Anderson (1991) calls an 'imagined community' of nation. Moreover, Fish's interpretative community is composed of people who do not necessarily know one another but who share norms. Similarly, Anderson's imagined community is comprised of people who do not know one another but who share a system of belief. It is reasonably clear that the essentialist approach would be very difficult to apply either to 'knowing' the foreign individual who is the object of identity work or to the fluctuating groups more or less actively or passively involved in the construction of that identity. Far more knowable is the discourse produced and interpreted by these communities. The following analysis reflects a constructivist approach based on the conviction that "who we are to each other [...] is accomplished, disputed, ascribed, resisted, managed and negotiated in discourse" (Benwell \& Stokoe, 2006, p. 4). The data will be analysed not for what it reveals about the out-group member's 'identity' but for the insights it provides into how the collective in-group identity is consolidated and renegotiated through its discourse concerning the 'other'.

\section{Narrative identity}

If, as Denzin (2000) claims, we live in a storytelling society, this data provides insights into the way the written media represents the nation to itself through the kinds of stories their 'national' spokespersons tell the 'nation' or the stories that society reads to itself in contexts involving issues of national identity. An aspect of narrative theory that is felt to be particularly relevant to the analysis is that of the macro-narrative or what Jones calls a 'storyline' (2004, p. 172). Jones describes these as broader, more general phenomena than narratives, which she describes as "relatively small and discrete." She describes how some "storylines [...] attain the status of normative or dominant storylines", and she provides a useful review of the terminology for theorising them: 
These powerful and prevalent storylines have been theorised variously as: culturally available narratives (Antaki, 1994), canonical narratives Bruner 1987, 1991), dominant discourses (Gergen 1995; Gee 1992, both cited in Talbot, Bibace, Bokhour \& Bamberg 1996) and master narrative (Mishler 1995), amongst other approaches. Whilst all these terms differ somewhat in their implications, concerns and underlying epistemology, I would argue that there is sufficient similarity between them to treat their existence as an acceptable working assumption (2004, p. 172).

Andrews states that "one of the key functions of master narratives is that they offer people a way of identifying what is assumed to be a normative experience" (Andrews, 2004, p. 1). Benwell and Stokoe provide a useful gloss to these comments:

Master narratives and/or discourses - of romance, change, respectability, tragedy, 'Cindarella' fairytales, stability, regression, masculinity, fatherhood, 'Rocky' masculine cultural models, masculine power - make available particular 'positions' or identity choices for the storyteller [....] they are out there shaping identity construction (Benwell and Stokoe, 2006, p. 158)

This analysis considers which cultural storylines and/or master narratives/discourses are implicated in shaping the identity construction of an Italian England Manager.

\section{Identity theory and the critical framework}

Benwell and Stokoe suggest that in narrative identity theory "analysts tend to reach into the intangible world of discourses and narrative genres to explain the local workings of narration" (2006, p. 158). The analysis in this paper follows an opposite, micro-macro trajectory: firstly to indicate the extent to which these wider cultural plotlines are interwoven with grammatical and lexical patterns that underlie mundane media discourse and secondly because analysis of such patterns can help reveal the rootedness of the insecurities that feed the big stories used for stereotyping out-groups. In line with van Dijk's (1990) seminal call for discourse analysis to "bridge the well-known gap between micro-and macro analyses of social phenomena" (cited in Fairclough, 1995), the bottom-up, analytical framework outlined here has been adopted to counterbalance the risk of making sweeping cultural assumptions that are not anchored in reasonably close textual analysis.

At the same time, to counterbalance criticism of the low generalisability of results in CDA (see Rasinger, 2010, p. 1022), the commentary attempts to complement close analysis with the quantitative methods of corpus analysis. Close textual analysis is conducted on two texts from each corpus by applying the various levels of the CDA analytical model outlined above. These findings are then used as a basis for analysing the remaining texts in the corpus using the Antconc concordancer software to verify consistent grammatical and lexical patterns involved in identity construction. 


\section{Transitivity}

In line with the multi-disciplinary nature of critical discourse analysis (Bloor \& Bloor, 2007, pp. 1-2), any insights into identity construction emerging from this paper are underpinned by a bottom-up approach, which starts with grammar and lexis.

Initially, the system of transitivity in each corpus is analysed. In the Systemic Functional Grammar developed by M.A.K. Halliday (1985), the concept of transitivity is more nuanced than in traditional grammars, where it refers to whether or not a verb takes a direct object. In the Hallydayan grammar, it refers to the entire system of combined verbal processes (material, mental, relational, verbal) from which speakers or writers choose "when encoding experiential meanings: meanings about the world, about experience, about how we perceive what is going on" (Eggins, 2004, p. 249). Transitivity structure corresponds to just one dimension of the systemic functional grammar. The mood structure, for example, accounts for how interpersonal meaning is constructed, i.e. how grammatical choices are responsible for particular kinds of interactions between participants in a conversation, say, or between text producer and text interpreters in written texts; textual meaning, on the other hand, concerns the grammatical choices involved in making it possible to negotiate texts as texts.

Systemicists argue that these three metafunctions (ideational, interpersonal, and textual (Eggins, 2004, p. 213) operate simultaneously, each corresponding to an aspect of the situation, or context, that independently has consequences for the linguistic choices made. Halliday (cited in Eggins, 2004, p. 90) divides these as follows:

- Field: what the language is used to talk about

- Tenor: how language defines the relationships between people involved in the situation (Taylor, 1998, p. 327)

- Mode: the role language plays in the interaction.

Halliday calls these aspects of communication 'register variables'. As identity construction is performed largely through what is said about Capello, it is closely bound up with the register variable of field. Consequently, the main focus of this research is the corresponding ideational metafunction, expressed through the transitivity system across the three corpora.

From the systemicist perspective, "when people use language, their language acts produce, or more technically, construct meaning" and "grammar becomes a study of how meanings are built up through the choice of words and other grammatical sources" (Bloor \& Bloor, 2004, p. 2). What makes the analysis more revealing as far as cultural attitudes to 'the other' are concerned is the knowledge that "it is not that the author has made a conscious choice among the available forms. He has created his meaning by drawing on the forms that are available to him as a speaker/writer, partly consciously (as a professional writer) and partly without reflection (as a native speaker)" (Bloor \& Bloor, 2004, pp. 3-4). 


\section{Lexis}

The importance of lexical scrutiny for CDA is widely accepted among its theorists (see Fairclough, 1995; Benwell \& Stokoe, 2006; Joseph, 2006). This commentary focuses on recurrent or associated vocabulary collocations, on the "little words [that] can flag the homeland" (Billig, 1995, p. 106) and on the words that constitute "the deixis of homeland" (Billig, 1995, p. 107). In systemic functional grammar, a deictic corresponds to a determiner, a demonstrative pronoun as well as to a possessive noun and a pronoun or even to an indefinite article (see Bloor \& Bloor, 2004, pp. 140-145). The three main kinds of deixis are space deixis, temporal deixis, and identity deixis (see Benwell \& Stokoe, 2006, pp. 253-256). The term is derived from the Greek for 'pointing'. An analysis of how texts 'point' at Capello when using forms of identity deixis such as 'he', 'the Italian', 'Capello', etc. is regarded as relevant to an analysis of how his identity is constructed. Michael Billig claims that "newspapers employ a routine deixis which is continually pointing to the national homeland as the land of its readers" (Billig, 1995, p. 11). The analysis of identity deixis shows how this can also be achieved through the manner in which the foreigner is pointed at or pointed out to the 'national' readers.

Examples of intertextuality and interdiscursivity also enter into this level of analysis, particularly because intertextual references are often a means of linking the reporting and commentary in the articles to the larger "cultural storylines" (Benwell \& Stokoe, 2006, p. 43) of which they are consciously or unconsciously a part.

\section{Corpus 1}

\section{Transitivity: Texts 1 and 2}

Text 1, "Barwick: Fans Deserve Fabio" (The Sun, 18 December, 2007) is a standard report about the press conference at which Capello is unveiled as the new England manager. Analysis of the text shows that Capello's identity is mainly established through three material processes: "he has coached and [he has] won titles" and "he has man-managed some of the world's [sic] best players." Each instance emphasises Capello's role as Actor, a function consolidated by the presence of goals in two them: "titles" and "some of the world's [sic] best players". The impression conveyed, therefore, is one of dynamism and achievement, particularly when contrasted with the processes that represent the FA and its chief executive. Predictably, there are instances in which they are identified as Actors: "after finally capturing his man", "I took time to think about the attributes", "I wasn't just seeking a name". However, this is far from uniform. For instance, although the first sentence "Barwick, who was handed the job of finding a world-class manager [...]" contains a material process, it is also an unagented passive and casts Barwick in the role of Patient. The FA board is most extensively identified through mental processes: "we know", "we knew", "Brian Barwick believes", "we believe", "Trevor Brooking and I were always clear about", in which the subjects emerge as Sensers as opposed to Actors, the prevalent participant role being assigned to Capello. 
Relational processes are also prominent in conveying the identity of Barwick and the FA: "I am delighted", "we are delighted", which depict the FA as Carriers rather than Actors.

Text 2, "The Italian Mob: FA land Capello but have to take on his entire coaching staff" (Lawton, The Daily Mail, 14 December, 2007), is more polemical. Close examination of the processes in this article reveals consistencies with the previous one. Capello is identified through a material process ("Capello could fly back to London today") and a mental process ("Capello wants a director of football"). In contrast, the FA is characterised by relational processes: "the FA are concerned", for example. In the sections of text that report other English managers' responses, Steve Coppell identifies himself through relational processes: "I'm sad, I'm a proud English manager!" and through mental processes in the conditional "I would have loved to have an Englishman in charge", "as an Englishman, how would you like an Italian coming in and taking your job?". Gareth Southgate expresses himself with a mental process: "I don't see the point of international football" and in his sole material process, the goal is defined as negative: "We have created a situation [...] where it is very difficult for an English manager to get to the top of the tree." His final statement is the conditional relational "it should be a player, coach [...] from that country". To define the representations in both texts in terms of van Leeuwen's (2008, p. 277) 'role allocation' model, the transitivity patterns used to identify Capello largely enact "activation", namely "when social actors are represented as the active, dynamic forces in an activity", while the remaining Sensers and Carriers are not nearly as 'activated' but are characterised by a greater degree of "passivisation" (see van Leeuwen, 2008, p. 278).

\section{Lexis: Texts 1 and 2}

Analysis of the lexis used in Text 1 confirms that professional identity is the main focus. The following lexical items are applied to Capello: "calibre", "qualities", "repute", "attributes", as are collocations like "world-class manager", "world-class status", "winner with a capital W", and "of proven pedigree".

The deictics of the final sentence - "That was the template and this is the man - Fabio Capello" - place the emphasis squarely on qualifications and professional capacity. Elsewhere in the text, we find the identifying process "Fabio is the man", where "Fabio" is the Identifier and "the man" is the Identified. In Barwick's words, Capello's distinction lies in his being uniquely qualified for the job. In the direct speech segments, Capello is referred to by his first name twice and by his full name twice, a form of linguistic politeness signalling the extent to which he is now part of the FA in-group. The anaphoric "he" is also used twice. This contrasts to the brief segment of "straight" reporting in which the journalist achieves reference using the bald surname and the co-reference "the Italian", suggesting an alternative way of mediating identity in this discourse, one that involves a shift from professional identity to national identity, the option taken in Text 2.

As is apparent from the headline "The Italian mob", the lexis of national identity is more marked in the second article, which foregrounds the news that Capello intends to bring in 
an all-Italian coaching staff. "Italian" is used twice, once collocating with "mob", a predictable example of national stereotype. Names are also prominent in the text: Italian names total five, while English names total four. "Englishman" is used three times; "England" is used four times, and "English" occurs four times, once in the collocation "proud English manager". That this may be more than just 'straightforward' factual reporting is suggested by the closing quote from Derby manager Paul Jewel - "If you put an 'o' at the end of his name, then he is going to be good, isn't he?" - a statement that underscores the emphasis on national stereotypes elsewhere in the article.

A degree of what van Dijk (2008) calls 'outgroup derogation' would appear to be achieved through textual cohesion. In the second text, Capello is repeatedly referred to with the co-reference "the Italian". This can easily be justified by its conciseness, an important consideration for co-textual reasons, though, as other forms of co-reference are available, it is also possible to see it as discursive in intent.

\section{National identity narratives}

In Text 2, national pride and resentment are expressed through stereotyped narratives that intertwine to adumbrate a modern-day tapestry of foreign invasion: the solitary interloper is not alone; Italians now threaten to overrun English football and constitute a threat to this expression of national identity. On a small scale, this corresponds to the clichéd rejection of the 'let one in, and the country will soon be overrun' and 'they're coming over here and taking our jobs!' sort (see Rasinger, 2010 for a detailed commentary on this macronarrative). The second narrative strand is that of the Italian mobster making the FA an offer it can't refuse. However, the reverse side of the negative depiction of the foreign identity would appear to be a loss of confidence in the host nation's own identity. This particular narrative emerges even more clearly in the second corpus of texts.

\section{Transitivity in the corpus}

The following table indicates that transitivity patterns across Corpus 1 substantially confirm the active identity ascribed to Capello in Texts 1 and 2. Although this is predictable, as he is the focus of the news, the ratio of processes, particularly of material processes, stresses his identity as an Actor.

\begin{tabular}{|l|r|r|r|r|r|}
\hline Subject & Total & Material & Mental & Relational & Verbal \\
\hline Capello & 82 & 47 & 9 & 12 & 14 \\
Barwick & 16 & 7 & 2 & 1 & 4 \\
English FA & 14 & 5 & 2 & 4 & 3 \\
England Team/squad & 16 & 8 & 2 & 6 & \\
\hline
\end{tabular}

Table 1: Transitivity ratios in Corpus 1 


\section{Lexis and narrative identities in the corpus}

Concordances of the first corpus substantially confirm the identity work outlined in the above two texts. As the following table shows, other collocates for Italian are interesting in that they confirm criminal stereotypes and also indicate how swiftly the press slips into negative nationalistic identity construction mode.

\begin{tabular}{|ll|}
\hline Italian mob & 2 \\
Italian job & 1 \\
Don Fabio & 4 \\
Boss of bosses & 1 \\
Capo di capi & 1 \\
Godfather & 3 \\
\hline
\end{tabular}

Table 2: Criminal connotations of 'Italian' in Corpus 1

The "Italian Mob" suggests that the all-Italian coaching staff is an issue for the English press. A search along these lines highlights the opposition, as shown in the following table.

\begin{tabular}{|lcll|}
\hline Italian coaching team & 1 & English voice & 1 \\
Italian backroom staff & 2 & English presence & 2 \\
countrymen & 1 & English influence & 1 \\
four of his Italian mates & 1 & English coach & 2 \\
pals & 2 & \\
four cronies & 1 & \\
\hline
\end{tabular}

Table 3: Italian vs English presence in the new setup

This would seem to tie in with the cultural storyline of an uncontrollable influx of foreigners taking jobs from nationals. A cross-corpus analysis of lexical patterns reveals that the cumulative identity discursively constructed for Capello intertwines two rather invidious stereotypes: economic migrant (albeit a rich one) and member of a criminal organisation. These narrative strands are woven out of diverse elements (transitivity, lexis, deixis, intertextuality), diffused through the online written media rather than concentrated in one text, which suggests that identity construction is a cross-referential effort, through which, to quote Billig "the sports pages [...], day after day, invite 'us' the readers to support the national cause" (1995, p. 11). 


\section{Corpus 2}

\section{Transitivity: Texts 1 and 2}

In the first text, "England football manager Fabio Capello's boot camp" (Ward, The Mirror, 5 February, 2008), the processes correspond to the new regime scenario. Most material processes in the text are attributed to Capello, the Actor of the following material processes: "took charge of his first training session", "commands a lot of respect", "sat with FA bigwig", "[i]s cracking the whip", "did not speak to any of the stars", "transformed the luxury spa [...] into a boot camp". A further series of material processes represent the players as the Patients of Capello's action: "gave our pampered stars a rude awakening", "whips our underachieving millionaires into shape", "has ordered them to be at dinner at $8 \mathrm{pm}$ prompt", "the new manager has cracked down on players' diets", all representations that confirm them in the role of "passivated social actors" (van Leeuwen, 2008, p. 279).

The ratio of material processes ascribed to England's players is much lower: "Players turned up", "They all came in and sat down together", "a few shook his hand". Elsewhere the processes are mental: "we don't know much about him", verbal: "the players admit it has come as a culture shock", or relational: "Everyone's nervous". It is significant that, in material processes such as "they were permitted 45 minutes in the games room" and "they weren't allowed to order luxuries", the players once more are Beneficiaries/Patients of unagented material processes.

The distribution of processes in Text 2, "Fabio Cracks the Whip" (Joyce, The Express, 2 February, 2008), reveals consistencies with Text 1 . More than any other participant, the new manager is identified through material processes: Capello "will [...] crack the whip", "[is] planning an even more intensive schedule", "will outline his ideas", "looks to resurrect their miserable fortunes". In a significant proportion of material processes, the country's stars are identified as his Beneficiaries: "try to turn them into winners", "will leave the country's stars in no doubt" while they are Patients in "immerses them into a no-nonsense regime". The only relational process used to identify Capello is the categorical "Capello is adamant". In contrast, the English players are identified collectively through a sole material process: "the rest of the party will undergo a double training session" - which is nevertheless nearer a passive in that they are presented as Patients - and the relational process "players have been used to just one training session".

\section{Lexis: Texts 1 and 2}

In Text 1, "Italian" occurs just once, in the collocation "Italian taskmaster". There are five instances of "Capello", but this would not appear to be an example of derogation because it collocates with the noun phrases "new coach", "new manager", "new supremo", twice with "England Boss", and twice with "England manager". This appears to mark a recognition of Capello's professional status and corresponds to what van Leeuwen (2008, p. 288) calls 'functionalisation', in which "social actors are referred to in terms of an activity, in terms of something they do, for instance an occupation or a role." The main opposition now 
appears to be a professional one rather than between nationalities: between the "taskmaster" associated with "no-nonsense rules" and the "iron fist" and "cracking the whip" on the one hand and "pampered stars", "our underachieving millionaires" on the other.

The deixis is also indicative of status, with the new manager indicated by name and role whereas individuals on the England squad are subsumed into the collective plural noun "players", in line with the scenario in which the 'dictator's' personality is the one that counts.

The second text reveals broadly similar patterns of identity work. "Italian" occurs just once; the manager's full name is used once; his given name is used once, and his surname is used three times. Functionalisation continues as Capello is identified as the "England boss" while prepositional phrases like "in charge" underscore his professional standing. As in the first text, the lexis of authority is prominent: "whip" and "regime" - premodified by "no-nonsense" - both reoccur. The players, on the other hand, are identified by reference to "their comfort zone".

\section{Transitivity in the corpus}

A search of processes in Corpus 2 appears to confirm the ratio of relationships emerging in Texts 1 and 2.

\begin{tabular}{|l|r|r|r|r|r|}
\hline Actor & Total & Material & Mental & Relational & Verbal \\
\hline $\begin{array}{l}\text { Capello: } \\
\text { New boss }\end{array}$ & 89 & 51 & 10 & 4 & 24 \\
$\begin{array}{l}\text { New coach } \\
\text { New man }\end{array}$ & & & & & \\
\hline $\begin{array}{l}\text { England: } \\
\text { Team }\end{array}$ & 20 & 10 & 5 & 3 & 2 \\
$\begin{array}{l}\text { Stars } \\
\text { Squad } \\
\text { Players }\end{array}$ & & & & & \\
\hline
\end{tabular}

Table 4: Transitivity ratios in Corpus 2

This distribution of processes indicates a shift from what van Leeuwen $(2008$, p. 288) calls 'identification', which occurs "when social actors are not defined in terms of what they do, but in terms of what they more or less permanently or unavoidably, are."

\section{Lexis in the corpus}

The shift in emphasis from national identity to professional identity in Texts 1 and 2 is reflected in patterns across the corpus. Capello is still identified through national identity, though there are far fewer references to invidious national stereotypes: 
Article: 'Don Fabio' and the taming of the three lions

\begin{tabular}{|l|r|}
\hline Deictical Form & Frequency \\
\hline Capello & 90 \\
Fabio Capello & 32 \\
New England manager, coach, supremo, boss etc., & 18 \\
The Italian & 12 \\
\hline
\end{tabular}

Table 5: Ratio of professional versus national identity in Corpus 2

What is more, as the following table indicates, his identity as a professional in authority is further bolstered by reoccurrence of the lexis of authority throughout the corpus. In contrast, the lexis employed for the players is consistently associated with the opposite qualities:

\begin{tabular}{|c|c|c|c|c|c|}
\hline \multicolumn{3}{|l|}{ Capello } & \multicolumn{3}{|l|}{ England Players } \\
\hline Lexical Item & Collocation & Frequency & Lexical Item & Collocation & Frequency \\
\hline authority & stamp & 1 & stars & pampered & 1 \\
\hline \multirow[t]{8}{*}{ discipline } & lack of & 1 & & underachieving & 1 \\
\hline & strict sense of & 1 & & underperforming & 1 \\
\hline & distance & 1 & & overrated & 1 \\
\hline & a great point of & 1 & & mollycoddling of & 1 \\
\hline & a bit of & 1 & underachievers & overrated & 1 \\
\hline & and form & 1 & players & pampered & 1 \\
\hline & basic & 1 & & mollycoddled & 1 \\
\hline & new-found & 1 & pampered & footballers & 1 \\
\hline \multirow[t]{4}{*}{ regime } & tough & 3 & & backsides & 1 \\
\hline & professional & 1 & school & new & 2 \\
\hline & austere & 1 & & first day at & 2 \\
\hline & hard & 1 & & big & 1 \\
\hline rule & iron & 1 & charges & new & 1 \\
\hline \multirow[t]{2}{*}{ iron } & rod of & 1 & & & 1 \\
\hline & fist & 2 & & & 1 \\
\hline
\end{tabular}

Table 6: Lexis of discipline versus indiscipline in Corpus 2 


\section{Identity narratives in the corpus}

The second corpus apparently marks a clean break from the stereotyped narratives prominent in the first corpus. Capello is now seen as a moral force puncturing the posturing of his pampered charges, transformed from a Mafia boss mugging the unsuspecting nation into a puritan disciplinarian, punishing the team who have betrayed their 'people', combining at a stroke the sacred and profane connotations of the Italian honorific 'Don'. Capello has morphed from interloping criminal mastermind into stern English headmaster. In The Sunday Times, Barnes (2008) points out that "Capello has been exhorting obedience from his charges as if they were new boys at school." The Daily Mail (2008) describes how the squad assembles under his "icy stares" and concludes "little wonder that the nervous schoolboys are on their best behaviour." A further trace of the castigation and expiation motif is found in The Times (2008), which refers to Capello as "the devout Roman Catholic [...] determined to run the England team in the manner of a monastery."

Samuel (2009) acknowledges that the mediated image of Capello corresponds above all to a collective desire to punish the players who have betrayed the imagined community's sense of identity:

We do not know much about Fabio, except he is one hard bastard. That is what we love about him, too. The nation is collectively high on the thought of Fabio kicking pampered backsides, stepping on prissy, privileged toes, whipping England's overrated underachievers into shape.

Possibly one of the most interesting findings is how the press both identifies an 'other' not only in the form of a foreigner but also in the shape of an inner 'other', the players themselves, who, as implied representatives of a social class, are responsible for undermining and betraying 'national' identity and who are thus deserving recipients of correction and discipline.

\section{Corpus 3}

\section{Transitivity: Texts 1 and 2}

In Text 1, "Fabio Capello gives England new ring of confidence" (Martin, The Times, 17 October, 2008), Capello, the Actor, is in evidence again: "Capello correctly identified a lack of confidence", "He took control", "he set about correcting this", "he has given his payers mental strength".

Players are identified through a much lower number of processes: as the Sayer in the verbal process "Rio Ferdinand hinted" and "players are crying out". By and large though, they are Beneficiaries, a relationship encapsulated by the clause: "He has given the players the mental strength". Attitudes to the national team are also revealed in the clauses where players are the Patients of doubts that act on them: "doubts that have plagued them" or when they are Beneficiaries of unagented passives: "crying out to be reacquainted with the basic skills" or of the agented "every individual appears to be benefiting from Capello's no-nonsense 
approach". Significantly, players appear as Actors most frequently by implication, when their identities are subsumed into the first-person plural used by Capello in the following mental and relational processes: "we always think we can score", "we have the confidence now".

The second text, "Fabio Capello preaching to the newly converted" (Barnes, The Times, 21 November, 2008), written following England's away victory in a friendly against Germany, reveals the symbolic force of the result through the extent to which the article reverses some of the transitivity patterns identified in the previous corpora. The distribution of processes indicates the extent to which the English team has been empowered by Capello. For the first time, the England team are identified through more material processes than is the manager: "The England team have abandoned their clown's jalopy, they are cruising", "England's second team [...] went to Germany and won".

Another development is the appearance of the inclusive "we" as the Senser in mental processes in which Capello is presented as the phenomenon of belief - as is the national team: "we believe in Capello", "we believe in England". Hitherto-sceptical journalists are also identified as Sensers in mental processes in which England is conveyed as the phenomenon of belief: "they think England will win the World Cup".

Capello is identified through just two relational processes: "Capello is untouchable" and the rather strange "Capello is the Lady Penelope of the new world", a surprising intertextual reference to the cult children's television series Thunderbirds (analysed in the section on lexis). Furthermore, in the elliptical relational process, "somewhere between God and Sir Alf Ramsey", Capello is compared with Alf Ramsey, the manager who steered England to its first and only World Cup victory against the then-West Germany in 1966, arguably one of the few remaining landmarks of something resembling 'national greatness' in the collective consciousness.

\section{Lexis: Texts 1 and 2}

Analysis of deixis deployed in Text 1 reveals a complete absence of "the Italian", with "Fabio Capello" being used twice and the surname four times. "England" is used four times, with "his players" used as a substitution device, indicating that Capello has made the team his own. There is less of a sense of opposition than in the previous two corpora. Analysis of the second text also reveals a decrease in the deixis of difference and derogation. "The Italian" does not occur in this text either: The complete name is used twice, and the surname is used four times. There is, however, a significant new element of deixis: "we" - presumably denoting England supporters, though it is possibly inclusive enough to encompass all Englishmen and women - and "they" referring to football writers, rather than to members of a foreign out-group.

\section{Intertextuality and narrative identity}

In both of these texts, Capello is compared to other celebrities who are emblematic of 'national' greatness. Text 1 begins with a reference to Sir Edmund Hillary, the New Zealander and - by virtue of that fact - British citizen, who was the first to scale Mount Everest 
and is said to have marked the occasion by planting the Union Jack. The thinking behind the comparison is that symbolic acts such as scaling Everest for 'one's' country can only be achieved by conquering self-doubt. Hillary's point about the conquest of the self appears to tie into the sense of the fraying fabric of society as being related to a decline in individual moral fibre, of which the England team were prime exemplars in the second corpus and from which they are shown to be recovering here. Capello seems to have been (albeit briefly) admitted to the gallery of greats (not necessarily 'English' at all) who symbolise British (but by implication English) endeavour and achievement.

The somewhat perplexing comparison with the puppet of a female aristocrat is relatively easy to explain. In the children's television programme Thunderbirds (1965), Lady Penelope, one of the team dedicated to averting global disaster, is chauffeur-driven around a futuristic London in a shocking pink Rolls Royce bearing the personalised number plate FAB1. From the very first, the tabloid press had been quick to exploit the abbreviation of Capello's first name, as though it heralded a return to the sixties - an era of considerable popular cultural hegemony - or to the more recent period of 'Cool Britannia', the memory of which had not entirely faded in 2007.

Despite its frivolity and banality (though it is Billig's (1995) and Edensor's (2002) contention that cultural trivia contributes significantly to the construction of national identity), this suggests that Capello is not only identified with England the team but also with England as a culture through comparison with two enduring symbols of 'Englishness', albeit from opposite ends of the cultural spectrum.

\section{Transitivity in the corpus}

The relational process is most frequently used to identify Capello in this corpus. This is particularly appropriate in a corpus focussed on 're-identification' of who Capello is, who he is heir to, who he is like, as a way, so to speak, of verifying his credentials for naturalisation. A significant number of these relational processes are used to indicate resemblances to Alf Ramsey or to make comparisons with other previous managers.

\begin{tabular}{|l|r|r|r|r|r|}
\hline & Total & Material & Mental & Relational & Verbal \\
\hline Capello & 30 & 9 & 1 & 20 & 0 \\
\hline
\end{tabular}

Table 7: Transitivity ratios for Capello in Corpus 3

\section{Lexis in the corpus}

Analysis of lexis in the rest of the corpus reveals that the language of opposition gives way to the language of similarity and comparison. "The Italian" occurs just seven times, while "Capello" is now used only slightly less often than the total number of names of former England managers. The repeated comparisons with Sir Alf Ramsey, for example, suggest that the discursive naturalisation of the foreigner is now complete. This would appear 
to indicate a reversal in which Capello, "the mysterious stranger who comes to redeem England", is crucially interpreted as doing so by embodying the qualities of the very man who last reawakened the spirit of 'authentic' national identity - the spirit of 1966 - in the national football squad.

\begin{tabular}{|lr|}
\hline Capello & 46 \\
Ramsey & 26 \\
Eriksson & 11 \\
McClaren & 8 \\
Greenwood & 5 \\
Hoddle & 2 \\
Taylor & 1 \\
Keegan & 1 \\
\hline
\end{tabular}

Table 8: Frequency of English managers named in corpus

\section{Concluding remarks}

Fairclough $(1995$, p. 16) points out that "media reception research has suggested that texts do not have unitary meanings but are quite variously interpreted by different audiences and different audience members and can be quite various in their effects." However, Fairclough (1995, p. 15) also suggests that "textual analysis can give access to the detailed mechanisms through which social contradictions evolve and are lived out and the sometimes subtle shifts they undergo." By combining qualitative critical discourse analysis with quantitative corpus-assisted analysis, this commentary has outlined a restricted number of linguistic mechanisms that form links in text chains that combine in a text network for this particular kind of discourse. This does not mean that any particular claims can be made about audience reception, but it does suggest that the online print media operate in strikingly similar and coherent ways that influence reception of an issue like national identity in the context of sport.

The most obvious expression of consistency is that the collective sports media response to Capello's appointment follows a trajectory of rejection, expectation, and 'naturalisation'. The first phase is characterised largely by what Wodak et al. (2009, p. 33) call 'dissimilation', which "implies the affixing of undifferentiated and usually derogatory labels on the group concerned." To this phase belong the racially stereotyped narratives of the Mafia boss and the economic migrant. The phase of expectation actually shows evidence of 'assimilation' (Wodak et al., 2009, p. 33), with the new regime introduced by Capello eliciting comparisons with national cultural symbols such as the school headmaster involved in a narrative 
of chastisement. Success in the job is greeted with a degree of 'naturalisation', by which Capello is associated with symbols of national 'greatness' and cultural hegemony.

At the same time, the bottom-up analysis has helped unpack other cultural plotlines directed at negatively stereotyping particular sub-groups within the national in-group, namely the players in the national squad, particularly in the phase of Capello's assimilation.

A further level of consistency can be traced in the transitivity and lexical patterns underlying each of the above phases. These indicate the extent to which misgivings about ingroup identity are interwoven into the very texture of this discourse. Patterns of transitivity repeatedly ascribe power and dynamism to Capello and attribute impotence and stasis to both the FA and the England team and, by implication, to English society as a whole, given that football, through the 'sporting fallacy', is accepted as an index of the 'health' of a national culture.

Finally, the analysis indicates how narrative strands are woven from diverse grammatical, lexical, and intertextual chains diffused throughout the texts comprising each corpus. Tracing how grammar and lexis intertwine in coherent narrative threads across diverse texts has made it possible to follow the contradictory and conflicting forms these narratives take in the sports written media and to appreciate the role they play in defining national identity and in ascribing identities to whoever is felt to threaten or restore it.

\section{References}

Anderson, B. (1983). Imagined Communities. London \& New York: Verso.

Andrews, M. (2004). Opening to the Original Contributions. In M. Bamber \& M. Andrews (Eds.), Narrating, Resisting, Making Sense (pp.1-6). Amsterdam \& Philadelphia: John Benjamins.

Beard, A. (1998). The Language of Sport. London: Routledge.

Benwell, B. \& Stokoe, E. (2006). Discourse and Identity. Edinburgh: Edinburgh University Press.

Billig, M. (1995). Banal Nationalism. London: Sage.

Bloor, M. \& Bloor, T. (2007). The Practice of Critical Discourse Analysis. London: Hodder Education.

Collinson, P. (1969). The Italian Job. U.K.: Paramount Pictures.

Denzin, N.K. (2000). Foreword. In M. Andrews, S. Day Scalter, C. Squire, \& A. Treacher (Eds.), Lines of Narrative: Psychological Perspectives (pp. xi-xiii). London: Routledge.

Edensor, T. (2002). National Identity, Popular Culture and Everyday Life. Oxford: Berg.

Eggins, S. (2004). An Introduction to Systemic Functional Linguistics ( $2^{\text {nd }}$ edition). London \& New York: Continuum.

Eckhert, P. \& McConnell-Ginet, S. (1992). Think practically and look locally: language and gender as community-based practice. Annual Review of Anthropology, 21, 461-490.

Fairclough, N. (1995). Critical Discourse Analysis. Harlow: Longman Group Ltd.

Fairclough, N. (1995). Media Discourse. London: Arnold.

Fairclough, N. (2001). Language and Power. London: Longman.

Fairclough,N. (2003). Analysing Discourse: Textual Analysis for Social Research. London \& New York: Routledge.

Fish, S. (1980). Is There a Text in This Class? Cambridge, MA: Harvard University Press. 
Halliday, M.A.K. (1985). An Introduction to Functional Grammar. London: Arnold.

Jones, R.L. (2004) 'That's very rude, I shouldn't be telling you that.' Older women talking about sex. In M. Bamber \& M. Andrews (Eds.), Narrating, Resisting, Making Sense (pp.169-190). Amsterdam \& Philadelphia: John Benjamins.

Joseph, J.E. (2006). Identity and language. The Encyclopedia of Lingusitics (pp. 486-491). Boston: Elsevier.

Kress, G. \& van Leeuwen, T. (1998). Front page: (the critical) analysis of newspaper layout. In A. Bell \& P. Garrett (Eds.). Approaches to Media Discourse (pp.186-209). Oxford: Blackwell.

Kress, G. \&, van Leeuwen, T. (2001). Multimodal Discourse: The Modes and Media of Contemporary Communication. London: Arnold.

McKay, S. (2006). Media and language: overview. Encyclopedia of Language and Linguistics. Boston: Elsevier. Petroni, S. (2011). Language in the Multimodal Web Domain. New York \& Ontario: ARACNE.

Porter, D. (2004). 'Your boys took one hell of a beating!' English football and British decline c. 1950-80. In D. Porter \& A. Smith (Eds.) Sport and National Identity in the Post-War World (pp. 31-51). Abingdon \& New York: Routledge.

Rasinger, S.M. (2010). Lithuanian immigrants send crime rocketing: representation of 'new' immigrants in regional print media. Media Culture \& Society, 32(6), 1021-1030.

Real, M.R. (2006). Sports Online: the newest player in mediasport. In A.A. Raney \& J. Bryant (Eds.). Handbook of Sports Media (pp. 171-184). New Jersey: LEA.

Taylor, C. (1998). Language to Language. Cambridge: Cambridge University Press.

van Dijk, T.A. (1990). Discourse \& Society: a new journal for a new research focus. Discourse \& Society, 1(1), 5-16.

van Dijk, T. (2008). Discourse and Power. Basingstoke: Palgrave Macmillan.

van Leeuwen, T. (2004). Ten reasons why linguists should pay attention to visual communication. In P. Levine \& R. Scollon (Eds.). Discourse and Technology: Multimodal Discourse Analysis (pp. 7-19). Washington, D.C.: Georgetown University Press.

van Leeuwen, T. (2008). The representation of social actors. In T.A. van Dijk (Ed.) Discourse Studies, 5 (pp. 268-302). London: Sage.

Wenner, L.A. (1998). Preface. In L.A. Wenner (Ed.). MediaSport (pp. xiii-xiv). London \& New York: Routledge. Wenner, L.A. (1989). Media, sports, and society: the research agenda. In L.A. Wenner (Ed.) Media, Sports, and Society (pp.13-48). Newbury Park: Sage.

Whitson, D. (1998). Circuits of promotion: marketing and the globalisation of sport. In L.A. Wenner (Ed.) MediaSport (pp. 57-72). London: Routledge.

Wodak, R., de Cillia, R., Reisigl, M., \& Liebhart, K. (2009). The Discursive Construction of National Identity (2 ${ }^{\text {nd }}$ edition). Edinburgh: Edinburgh University Press.

\section{Online Sources}

Barnes, S. (2008). In the beginning was the word and the English word was Boss. Retrieved December 5, 2011, from www.timesonline.co.uk/tol/.../article3315490.e.

Barnes, S. (2008). Fabio Capello preaching to the newly converted. Retrieved December 5, 2011, from: www. timesonline.co.uk/.../simon_barnes/article.

Harris, H. (2007). Canny Capello pulls off a master stroke. Express.co.uk. Retrieved December 5, 2011 from: http://www.express.co.uk/posts/view/28839/Canny-Capello-pulls-off-a-master-stroke.

Hughes, M. (2008). England squad introduced to strict new diet of formalities and discipline. Retrieved December 5, 2011, from: www.timesonline.co.uk. 
Joyce, P. (2008). Fabio cracks the whip. Retrieved December 5, 2011, from The Express.co.uk website: http:// www.express.co.uk/posts/view/33746.

Lawton, M. (2007). The Italian mob: FA land Capello but have to take on his entire coaching staff. Retrieved December 5, 2011, from Mail Online website: http://www.dailymail.co.uk/sport/football/article-502034/ The-Italian-mob-FA-land-Capello-entire-coaching-staff.html.

Lawton, M. \& Ashton, N. (2008). Stop playing with fear, Capello cracks the whip on England's underperformers. Retrieved December 5, 2011, from: http://www.dailymail.co.uk/sport/football/article-544110/ Stop-playing-fear-Capello-cracks-whip-Englands-underperformers.html.

Lovejoy, J. (2008). Fabio Capello drags England egos into line. Retrieved December 5, 2011, from the Times Online: https://www.search.zurich.com/web/rep/s/search/kno_quickview_popup.jhtml?docld=171092 \&Links=LOVEJOI,SVENGORAN,GORAN,EGO,ERIKSSON,SVEN\&image=thetimes.

The Sun (2007). Barwick: fans deserve Fabio. Retrieved December 5, 2011, from: http://www.thesun.co.uk/ sol/homepage/sport/football/592582/Barwick-Fans-deserve-Fabio.html.

Samuel, M. (2008). Fabio Capello gives England new ring of confidence. Retrieved December 5, 2011, from the Times Online: www.timesonline.co.uk/tol/.../article4958655.

Samuel, M. (2008). Plug is pulled on Game Boys as manager puts the frighteners on stars with new trials by video. Retrieved December 5, 2011, from the Times Online.

Ward, V. (2008). England football manager Fabio Capello's boot camp. Retrieved December 5, 2011, from: http://www.mirror.co.uk/news/top-stories/2008/02/05/england-football-manager-fabio-capello-sboot-camp-115875-20309806/.

Dermot Brendan Heaney

Tenured researcher, $P h D$

Humanities Department

The University of Rome 'Tor Vergata', Italy heaneydermot0@gmail.com 